\title{
ЛЮБОВНАЯ ЛИРИКА КАК ПРЕДМЕТ КОММУНИКАТИВНОГО АНАЛИЗА
}

\author{
Инна Зонтаг \\ LOVE LYRICS AS A SUBJECT OF COMMUNICATION ANALYSIS
}

\author{
Inna Sontag
}

\begin{abstract}
Резюме: В статье рассматривается специфика любовной лирики с точки зрения риторических позиций: характеризуются особенности уместного речевого анализа любовной поэзии, а также жанровый репертуар (внешний и внутренний) стихотворений о любви.
\end{abstract}

Ключевые слова: любовь, любовное общение, любовная лирика, жанры любовного общения.

Abstract: The article considers the specifics of love lyrics from the point of view of rhetorical positions: the features of appropriate speech analysis of love poetry, as well as the genre repertoire (external and internal) of love poems are characterized.

Key words: love, love communication, love lyrics, genres of love communication.

DOI: $10.14712 / 9788076032088.19$

Любовная поэзия является оригинальным литературоведческим феноменом, независимо от того, в какие времена к ней обращались мастера слова. Тема любви всегда интересовала людей творческих: они пытались раскрыть в своих произведениях уникальную природу феномена любви, неповторимого, таинственного и в связи с этим завораживающего. Наверное, нет в образцах современного и классического искусства художников, кто не отразил бы в этой теме свой опыт или хотя бы философское представление о нем. Не исключением является и художественная литература, ставшая своеобразной энциклопедией любви для вдумчивых и глубоких читателей. Однако литература о любви, в том числе поэзия, во многом исследована известными литературоведами и критиками (см. работы Э. Герштейн, Ю. М. Лотмана, А. В. Севрюк, Л. Б. Шнейдера и др.), если рассматривать ее как явление классической филологической науки. Совершенно иначе мы можем сказать о речеведческой характеристике данного феномена, так как риторическую природу стихотворений о любви не рассматривает практически никто. Анализ доступных нам источников показал, что в современной лингвистике любовная лирика не характеризуется как образец использования в ней свойственных любовному общению жанров речи, а, следовательно, авторитетные выводы о том, что любовная лирика может считаться идеальным речевым образцом, помимо литературного совершенства, никто не делает. Этим были обусловлены наш интерес к заявленной проблеме и актуальность изучения поднятого вопроса. В качестве основного направления своей работы мы выбрали исследование коммуникативной (и в частности риторической) сущности любовной поэзии (с учетом литературоведческого аспекта ее характеристики), а для этого нам необходимо было обратиться к различным понятиям речеведения, психологии, психолингвистики, чтобы определить рабочий терминологический минимум. Обратимся к его характеристике. 
Согласно словарю С. И. Ожегова, лирика - это род литературных произведений, преимущественно поэтических, выражающих чувства и переживания лирического героя, за образом которого зачастую представлен автор (Ожегов 1996). Соответственно, любовная лирика - это лирика, основной темой которой является любовь, а, следовательно, ее содержание связано с характеристикой сопутствующих поэтическому «сюжету» переживаний лирического героя и героини.

Анализ источников показал, что любовь как психолингвистическое понятие имеет несколько определений: 1) глубокое эмоциональное влечение, сильное сердечное чувство; 2) чувство глубокого расположения, самоотверженной и искренней привязанности. Э. Фромм в научном труде «Искусство любить» говорит о том, что любить - это делиться с любимым человеком всем, что у него есть, но прежде всего не материальными, а духовными ценностями. «Это отнюдь не значит, что он обязательно должен жертвовать жизнью ради другого, - просто он делится тем, что есть в нем живого: своей радостью, своими интересами, своими мыслями, знаниями, своим настроением, своей печалью - всеми проявлениями своей жизни» (Фромм 2014, 123).

Проанализировав позиции философов, психологов, лингвистов, мы пришли к выводу, что феномен любви трактуется в разных науках по-разному, с частных научных позиций, однако в меньшей степени это явление охарактеризовано с точки зрения жанрового репертуара общения влюбленных, тем более если речь идет о рассредоточенном использовании этих жанров в классических поэтических текстах, а ведь в силу речевого совершенства последних они могут стать блестящими образцами для представителей современного поколения, которое учится любить, бесконфликтно выстраивать отношения со своей второй «половинкой», конструктивным способом выходить из возможных любовных конфликтов и налаживать отношения с партнером.

В связи с этим в рамках своей работы мы решили обратиться к речевой стороне любовной коммуникации, охарактеризовав связанные с ней понятия. Так, мы сформулировали значение термина «любовное общение». Мы подразумеваем, что это взаимодействие коммуникантов, которые любят друг друга или у которых только зарождается это чувство. Отметим, что такое общение обязательно сопровождается специфическими вербальными, ритмико-интонационными и пантомимическими характеристиками речевого поведения двух любящих друг друга людей. Также обязательно учесть, что это общение невозможно без особого жанрового наполнения, явно указывающего на любовный характер взаимоотношений коммуникантов. Напомним, что под речевым жанром понимают «относительно устойчивые типы высказываний, соответствующие типу речевых ситуаций» (Бахтин 1979, 237). Анализ реальной речевой практики и произведений классической художественной литературы привел нас к выводу, что в любовном общении возможно два типа речевых жанров: конструктивные, то есть созидающие любовь, и деструктивные, разрушающие положительный контекст любовной коммуникации. К числу созидающих жанров любовного общения мы отнесли признание в любви, любовную клятву, обещание, извинение и др., а к числу деструктивных упрёки, грубые и часто необоснованные требования, обвинения и др. (Горбунова 2012). Охарактеризуем эти жанры подробнее и приведем ситуации их использования в любовной лирике.

Признание в любви - высказывание, содержащие в себе слова любви как доказательство истинности чувств коммуниканта. Этот жанр характерен только для любовного 
общения и предполагает обязательную ответную реакцию. Охарактеризуем образец этого жанра на примере любовной лирики В. Тушновой.

\section{Образец №1}

Я желаю тебе добра!

Улыбаюсь, а сердие плачет

в одинокие вечера.

я люблю тебя.

Это значит -

я желаю тебе добра.

Это значит, моя отрада,

слов не надо и встреч не надо,

и не надо моей печали,

и не надо моей тревоги,

и не надо, чтобы в дороге

мы рассветы с тобой встречали.

Bот и старость вдали маячит,

и о многом забыть пора...

Я люблю тебя.

Это значит -

я желаю тебе добра.

Значит, как мне тебя покинуть,

как мне память из сердиа вынуть,

как не греть твоих рук озябших,

непосильную ношу взявших?

Кто же скажет, моя отрада,

что нам надо,

а чтоо не надо,

посоветует, как же быть?

Нам никто об этом не скажет,

и никто пути не укажет,

и никто узла не развяжет...

Кто сказал, что легко любить? (Тушнова)

Признание в любви выражено в данном случае, казалось бы, банальной фразой «Я люблю тебя», однако далее эта фраза приобретает для героини более выразительный смысл. Для нее признание в любви - это пожелание добра своему любимому. А далее в строфе, начинающейся со слов «Значит, как мне тебя покинуть...», она еще более точно раскрывает суть своего признания, превращая все стихотворение в развернутую признательную метафору. Безусловно, микрожанрами, то есть минимальными, внутренними высказываниями, зачастую равными одному предложению, в признании героини становятся и фразы-пожелания, и ласковые обращения к любимому («моя отрада»), и риторические вопросы-замечания («Кто сказал, что легко любить?»). Но в комплексе они создают развернутое признание в любви, которое, безусловно, является совершенным речевым образцом и в аспекте отбора вербального содержания, и в аспекте интонационного рисунка текста.

Любовная клятва - жанр, который содержит в себе, помимо признания в любви, заверения в неоспоримости и нескончаемости последней. Зачастую использование этого жанра 
говорит о зрелости и силе чувства, возникшего между влюбленными. Проследим это на примере фрагмента из произведения У. Шекспира «Ромео и Джульетта».

\section{Образеч №2}

Джульетта: Я тоже бы себя сдержала - надо

Признаться в том - когда бы не подслушал,

Без моего ты ведома, моих

Любви признаний искренних. Прости же

Ты мне и в легкомыслии меня ты

Не упрекай за то, что только ночь

Тебе открыла темная случайно.

Ромео: Синьора, я клянусь луной святою,

Сребрящею верхи дерев, покрытых

Плодами...

Джульетта: Не клянися ты луною

Изменчивой луною, каждый месяц

Меняющею лик свой, - да не будет

Подобна ей твоя любовь!

Ромео: Так, чем же

Велишь мне клясться?

Джульетта: Не клянись совсем ты,

Иль милым существом своим, кумиром

Единственная моим ты поклянися

- И я поверю!

Ромео: Если сердиа страсть... (Шекспир)

В данной сцене Ромео клянется Джульетте в любви луной, однако Джульетта выражает сомнение, так как считает, что предмет клятвы не принесет ей уверенности в его словах (луна «изменчива»). Поэтому она просит Ромео не клясться вовсе или поклясться иначе. Как видно, сами предметы клятвы героя являются выразительным и нетривиальным содержанием этого жанра и могут стать примером для любящих людей, которые хотели бы уверить свою «половинку» в искренности чувств.

Обещание - речевой жанр, в котором высказывается обязательство, заверение того, что что-либо будет сделано, исполнено, дано. При использовании данного жанра один партнер уступает другому или оба приходят к компромиссу. Обратимся к стихотворению Эдуарда Асадова «Все равно я приду».

\section{Образец №3}

Если град зашумит с дождём,

Если грохнет шрапнелью гром,

Всё равно я приду на свиданье,

Будь хоть сто непогод кругом!

Если зло затрещит мороз

И завоет метель, как пёс,

Всё равно я приду на свиданье,

Хоть меня застуди до слёз!

Если станет сердиться мать

И отец не будет пускать, 
Всё равно я приду на свиданье,

Что бы ни было - можешь ждать!

Если сплетня хлестнёт, ну что ж,

Не швырнёт меня подлость в дрожь,

Всё равно я приду на свиданье,

Не поверя в навет и ложь!

Если я попаду в беду,

Если буду почти в бреду,

Всё равно я приду. Ты слышишь?

Добреду, доползу... дойду!

Ну, а если пропал мой след

И пришёл без меня рассвет,

Я прошу: не сердись, не надо!

Знай, что просто меня уж нет... (Асадов).

Главный герой обещает возлюбленной, что он придет к ней, несмотря ни на что, что ничего, кроме смерти, не помешает ему увидеться с любимой. Безусловно, даже цитирование стихотворения автора в реальной ситуации общения влюбленных может неоспоримо усилить эмоциональный эффект и дать понять адресату, насколько он дорог и близок своему любимому человеку.

Извинение - речевой жанр, в котором содержатся просьба о прощении или слова оправдания. Как показывает наш опыт наблюдений, извинение является одним из самых эффективных этикетных высказываний в ситуации любовного конфликта. Обратимся к стихотворению Игоря Северянина «Спустя пять лет (Тебе, Евгения)».

\section{Образец №4}

Тебе, Евгения, мне счастье давшая,

Несу горячее свое раскаянье...

Прими, любившая, прими, страдавшая,

Пойми тоску мою, пойми отчаянье.

Вся жизнь изломана, вся жизнь истерзана.

В ошибке юности - проклятье вечное...

Мечта иссушена, крыло подрезано,

Я не сберег тебя, - и жизнь - увечная...

Прости скорбящего, прости зовущего,

Быть может - слабого, быть может - гения.

Не надо прошлого: в нем нет грядущего,-

В грядущем - прошлое... Прости, Евгения! (Северянин).

Клишированное выражение «Прости...», многократно использованное в данном тексте, говорит о том, что автор искренне сожалеет о произошедшем. Эмоциональный эффект усиливается благодаря использованию и просьбы о возможности понять его («Пойми тоску мою, пойми отчаяние»), горького признания («Я не сберег тебя»), оценочных характеристик в свой адрес («Прости скорбящего, прости зовущего») и неоднократного обращения к возлюбленной по имени.

Подводя промежуточный итог, можно отметить, что представленный репертуар жанров обладает уникальным вербальным наполнением, выразительным, эмоциональным, точным, очень личным и искренним. При этом сами стихотворения, помимо включения в их состав 
речевых (обиходных, этикетных) жанров, обладают определенной жанровой принадлежностью. Например, это могут быть любовные послания или поэтические письма поэтов к своим возлюбленным, развернутые признания в любви, пожелания или стихотворные поздравления, в связи с чем можно сделать вывод о внешней и внутренней жанровой палитре любовной лирики. Безусловно, данные образцы могут стать своеобразным речевым уроком для всех влюбленных, которые хотели бы научиться выражать свои чувства. Однако в числе жанров любовного общения, если говорить о реальной коммуникации, а не о традиционных жанрах поэтического творчества, есть и те высказывания, которые содержательно носят негативный характер. Представим их краткий обзор, обратив особое внимание на возможность «смягчения» их вербального выражения в любовной лирике известных поэтов.

Упрек - речевой жанр, содержащий в себе слова недовольства, неодобрения, обвинения в чём-либо по отношению к действиям другого человека. При этом упрек может быть выражен по-разному: корректно или бестактно. Приведем пример стихотворения М. Ю. Лермонтова «Нищий», где жанр развернутого упрека представлен более выразительно, чем мы привыкли его наблюдать в реальной речевой практике.

\section{Образец №5}

У врат обители святой

Стоял просящий подаянья

Бедняк иссохший, чуть живой

От глада, жажды и страданья.

Куска лишь хлеба он просил,

И взор являл живую муку,

И кто-то камень положил

В его протянутую руку.

Так я молил твоей любви

С слезами горькими, с тоскою;

Так чувства лучшие мои

Обмануты навек тобою! (Лермонтов)

В этом стихотворении автор упрекает любимую девушку в обмане, сравнивая свое душевное состояние с положением просящего подаяния бедняка.

Обвинение - речевой жанр, содержащий в себе укор, который указывает на чью-либо вину и демонстрирует недовольство инициатора общения.

\section{Образец №6}

Мне о любви твердила ты шутя

И холодно сознаться можешь в этом.

я исиелен; нет, нет, я не дитя!

Прости, я сам теперь знаком со светом.

Кого жалеть? Печальней доля чья?

Кто отягчен утратою прямою?

Легко решить: любимым не был я;

Ты, может быть, была любима мною (Баратынский).

В представленном стихотворении автор обвиняет возлюбленную в том, что она его не любила и говорила об этом лишь шутя.

Требование - речевой жанр, содержащий конкретное указание на выполнение/невыполнение чего-либо. Адресант в таких ситуациях четко устанавливает рамки 
выбора, а диалог нередко сопровождается эмоциональными репликами и авторитарной тональностью общения.

\section{Образец №7}

Оставим это. Обещать одно

Мне должен ты. Коль в жизни доведется

Нам встретиться еще - не должен ты

Глазом моргнуть. Вот долг твой. Понял?

Еще одно: нигде и никогда

Не смей разузнавать под страхом смерти

Моей - кто я. Еще одно: люби

Другую, нет - других, нет всех. Безумства -

Три совершила я в свой краткий век.

Ты - третье и последнее. - Довольно (Цветаева).

Поэтесса прощается со своим возлюбленным, выражая это через требование. Она требует любить других и при встрече не реагировать на нее. Хотя вдумчивый читатель может заметить, что за этим требованием, возможно, скрывается противоположный контекст.

Таким образом, проведя небольшой аспектный анализ стихотворений о любви с включением в них жанров художественно преобразованного любовного общения, мы пришли к выводу, что и внешняя, и внутренняя жанровая специфика любовной поэзии позволяет назвать ее совершенным речевым образцом, который может преподнести урок современному поколению и научить его пользоваться всеми возможными средствами выразительного "обозначения» своих чувств.

Для того чтобы выяснить уровень понимания данного феномена студентами, обучающимися на факультете филологии, мы решили провести анкетирование. Представим использованный вариант анкеты.

1. Сформулируйте, пожалуйста, определение термина: «Любовь - это ...»

2. Назовите главные ассоциации/чувства, которые возникают у Вас при упоминании слова «любовь».

3. Как Вы понимаете значение словосочетания «любовное общение»? Дайте ему определение.

4. Прочитайте стихотворения А. С. Пушкина («Я вас люблю, хоть я бешусь») и А. А. Блока («Одной тебе, тебе одной»). Можно ли отнести ситуации, представленные в них, к ситуациям любовного общения? Почему?

\section{А. С. Пушкин}

Я вас люблю, - хоть я бешусь, Хоть это труд и стыд напрасный, И в этой глупости несчастной У ваших ног я признаюсь! Мне не к лицу и не по летам... Пора, пора мне быть умней! Но узнаю по всем приметам Болезнь любви в душе моей: Без вас мне скучно, - я зеваю; При вас мне грустно, - я терплю; И, мочи нет, сказать желаю,

\section{А. А. Блок}

Одной тебе, тебе одной, Любви и счастия царице, Тебе прекрасной, молодой Все жизни лучшие страницы!

Ни верный друг, ни брат, ни мать Не знают друга, брата, сына, Одна лишь можешь ты понять Души неясную кручину.

Ты, ты одна, о, страсть моя, 
Мой ангел, как я вас люблю!

Когда я слышу из гостиной

Ваш легкий шаг, иль платья шум,

Иль голос девственный, невинный,

Я вдруг теряю весь свой ум.

Вы улыбнетесь, - мне отрада;

Вы отвернетесь, - мне тоска;

За день мучения - награда

Мне ваша бледная рука.

Когда за пяльцами прилежно

Сидите вы, склонясь небрежно,

Глаза и кудри опустя, -

Я в умиленье, молча, нежно

Любуюсь вами, как дитя!..

Сказать ли вам мое несчастье,

Мою ревнивую печаль,

Когда гулять, порой, в ненастье,

Вы собираетеся вдаль?

И ваши слезы в одиночку,

И речи в уголку вдвоем,

И путешествия в Опочку,

И фортепьяно вечерком?..

Алина! сжальтесь надо мною.

Не смею требовать любви.

Быть может, за грехи мои,

Мой ангел, я любви не стою!

Но притворитесь! Этот взгляд

Всё может выразить так чудно!

Ах, обмануть меня не трудно!.

Я сам обманываться рад! (Пушкин)
Моя любовь, моя царица!

Во тьме ночной душа твоя

Блестит, как дальняя зарница (Блок).

5. Назовите основные жанры реального любовного общения. Использовались ли названные Вами высказывания в представленных для анализа стихотворениях? Приведите конкретные примеры из текстов.

6. Можно ли рассматривать фрагменты поэтических текстов о любви, в том числе предложенные вашему вниманию, как риторические, т.е. совершенные / идеальные, образцы любовного общения? Свою точку зрения поясните.

7. Назовите литературоведческие и речевые особенности любовной поэзии.

8. Произведения каких авторов, на Ваш взгляд, можно считать риторическими образцами любовной лирики?

В констатирующем срезе приняло участие 54 человека, студенты 2-4 курсов факультета филологии Новокузнецкого института (филиала) Кемеровского государственного университета. Выбор респондентов был обусловлен осведомленностью студентов в области литературы, их начитанностью и дальнейшей профессиональной деятельностью: в будущей педагогической практике им придется использовать различные виды анализа любовной поэзии на уроках словесности, а, следовательно, аспектные филологические знания им необходимы. 
Первый и третий вопросы анкеты были направлены на определение значений ключевых для нашего исследования терминов - любовь и любовное общение. Это было необходимо для того, чтобы в последующих вопросах более точно охарактеризовать специфику любовной поэзии. Второй, пятый, шестой и седьмой вопросы расширяли значение названных выше терминов с учетом их возможного использования в образцах любовной поэзии. Четвертый вопрос был направлен на конкретный анализ предложенных фрагментов и помог определить начитанность учащихся, их способность анализировать поэтические тексты о любви с учетом умения видеть особенности любовного общения и его жанры. В восьмом вопросе респонденты на основе своего речевого и литературного опыта должны были привести имена творческих личностей, поэзию которых можно считать риторическим образцом любовной лирики.

На основе результатов анкетирования мы сделали следующие выводы. У респондентов не возникло трудностей с определением понятий любви и любовного общения. Большая часть студентов верно определила значение минимального терминологического аппарата нашей работы.

При анализе ответов на второй вопрос мы выявили, какие ассоциации возникают у студентов при упоминании о любви. В их числе оказались: поддержка, забота, счастье, доверие, семья, страсть. Но были и такие ответы, которые связывались с отрицательными качествами человека: ненавистью, неприязнью. Это позволило нам сделать вывод о негативном любовном опыте коммуникантов.

В четвертом вопросе участники эксперимента продемонстрировали свой уровень эрудиции, анализируя предложенные художественные образцы. Студенты отнесли описанные в них ситуации к любовному общению, аргументируя это конкретным содержанием стихотворений. Процент неверных ответов оказался минимальным, что еще раз утвердило нас в мысли о присутствии у респондентов необходимого коммуникативного опыта.

Пятый вопрос позволил исследовать уровень владения респондентами информацией о жанрах любовного общения, и большинство студентов на уровне определения, понимания содержания таких высказываний оказалось не знакомо с ними. Однако ответы на шестой вопрос удовлетворили нас больше, так как респонденты выразили четкое представление о том, какие образцы любовной поэзии можно считать риторически совершенными, а какие - нет. В данном случае классическая и современная (новейшая) литература были противопоставлены. В числе поэтов, сумевших создать такие образцы, студенты в большинстве своем называли А. С. Пушкина, С. А. Есенина, А. А. Ахматову и М. И. Цветаеву.

В то же время ответы на седьмой вопрос показали, что студенты не могут назвать конкретных речевых (жанровых) и литературоведческих особенностей любовной поэзии, кроме использования в ней различных средств выразительности, что утвердило нас в мысли о необходимости изучать данный феномен на речеведческих занятиях в вузе с будущими учителями-словесниками.

Мы убеждены, что для корректного и детального анализа любовной лирики необходимо применять приемы не только литературоведческой интерпретации, но и риторической, так как любовная поэзия обладает спектром особенностей, характерных для реальной любовной коммуникации, а, следовательно, включает в себя определенный жанровый репертуар. Взяв за основу данное убеждение и опираясь на результаты эксперимента, мы сформулировали одно из перспективных направлений развития выбранной нами темы: разработать систему занятий по обучению студентов-филологов приемам корректного речевого и литературоведческого 
анализа образцов любовной поэзии. На наш взгляд, это усовершенствует уровень коммуникативной и аспектной предметной подготовки будущих учителей.

\section{Использованная литература/ References}

\section{Печатные источники:}

Герштейн, Э. (1997): Роман «Герой нашего времени» М. Ю. Лермонтова. Москва : ЧеРо, 1997. 130 с. ISBN 5-88711-034-1.

Горбунова, А. А. (2012): Любовная лирика М. Ю. Лермонтова под риторическим микроскопом: материалы II Международной научно-практической конференции / под ред. Л. В. Гордеевой, Т. Ю. Зотовой. Новокузнецк : РИО КузГПА, 2012. С. 66-71.

Даль, В. И. (2004): Толковый словарь живого великорусского языка : словарь / сост. Н. В. Шахматова. Москва : АСТ, 2004. в 4 т. 4518 с. ISBN 978-5-17-088243-4.

Ефремова, Т. Ф. (2000): Новый словарь русского языка : словарь. Москва : Русский язык, 2000. в 2 т. 1209 с. ISBN 978-5-200-02800-9.

Ожегов, С. И.; Шведова, Н. Ю. (1996): Толковый словарь русского языка. Москва : Азбуковник, 1996. 928 с. ISBN 5-86532-008-8.

Севрюк, А. В. (2006): Психосемантика выражения чувства любви в русской ментальности : диссертация канд. культурологических наук. Комсомольск-на-Амуре, 2006. 167 с.

Ушаков, Д. Н. (2008): Толковый словарь русского языка / под ред. Д. Н. Ушакова. Москва : АСТ, 2008. 1268 c. ISBN 978-5-17-048302-0.

Фромм, Э. (2014): Искусство любить. Москва : АСТ, 2014. 221 с. ISBN 978-5-17-084593-4.

Шнейдер, Л. Б. (2000): Психология семейных отношений. Курс лекций. Москва : Апрель-Пресс ЭКСМОПресс, 2000. 512 с. ISBN 5-04-005780-6.

\section{Онлайн-источники:}

АСАДОВ, Э. (онлайн): Все равно я приду [онлайн]. Режим доступа: https://rupoem.ru/asadov/esli-gradzashumit.aspx [дата обращения: 24.04.2020].

БАРАТЫнСКИЙ, Е. (онлайн): Размолвка [онлайн]. Режим доступа: https://rustih.ru/evgenij-baratynskijrazmolvka/ [дата обращения: 24.04.2020].

БАХТИН, М. М. (1979): Эстетика словесного творчества. Москва : Искусство, 1979. 424 с.

Блок, А (онлайн): Одной тебе, тебе одной [онлайн]. Режим доступа: https://rustih.ru/aleksandr-blok-odnojtebe-tebe-odnoj/ [дата обращения: 24.04.2020].

ЛЕРМОНТОВ, М.Ю. (онлайн): Нищий [онлайн]. Режим доступа: https://rustih.ru/mixail-lermontov-nishhij/ [дата обращения: 24.04.2020].

ЛОтМАН, Ю. М.; Успенский, Б. А. (онлайн): Письма русского путешественника / Ю. М. Лотман, Б. А. Успенский. Ленинград : Наука, 1984. 726 с. [онлайн]. Режим доступа: https://imwerden. de/pdf/karamzin _pisma_russkogo_puteshestvennika_1984_text.pdf. [дата обращения: 15.04.2020].

ПУшкИН, А.С. (онлайн): Я вас люблю, - хоть я бешусь [онлайн]. Режим доступа: https://rustih.ru/aleksandrpushkin-priznanie/ [дата обращения: 24.04.2020].

СЕВЕРЯНИН, И. (онлайн): Спустя пять лет [онлайн]. Режим доступа: https://rupoem.ru/severyanin/tebeevgeniya-mne.aspx [дата обращения: 24.04.2020].

ТУШНОВА, В. (онлайн): Я желаю тебе добра [онлайн]. Режим доступа: https://rustih.ru/veronika-tushnovaulybayus-a-serdce-plachet/ [дата обращения: 24.04.2020].

ЦВЕТАЕВА, М. (онлайн) : Оставим это [онлайн]. Режим доступа: https://rustih.ru/marina-cvetaeva-ostavimeto-obeshhat-odno/ [дата обращения: 24.04.2020].

ШЕКСПИР, У. (онлайн): Ромео и Джульетта [онлайн]. Режим доступа: http://romeo-andjuliet.ru/translations/grigorieva/page-6 [дата обращения: 24.04.2020]. 


\section{Профиль автора:}

Инна Зонтаг, студентка 3 курса фракультета филологии Новокузнецкого института (филиала) ФГБОУ ВО «Кемеровский государственный университет»

Научный руководитель: Любовь Викторовна Гордеева, кандидат педагогических наук, доцент Научные интересы: коммуникативная культура педагога-филолога, речевая практика современников, жанры речи, теория и методика обучения русскому языку и литературе, школьное и вузовское филологическое образование.

e-mail: lyuba.gordeeva.85@mail.ru

Место работы: Новокузнецкий институт (филиал) ФГБОУ ВО «Кемеровский государственный университет», факультет филологии, кафедра русского языка и литературы; г. Новокузнецк, ул. Радищева, д. 34, кв. 21, индекс: 654086, Россия.

\section{Author's profile:}

Inna Sontag, 3rd year student of the faculty of Philology of Novokuznetsk Institute (branch) Kemerovo state University

Scientific supervisor: Lyubov Viktorovna Gordeeva, candidate of pedagogical Sciences, associate Professor Research interests: communicative culture of a philologist, speech practice of contemporaries, genres of speech, theory and methods of teaching Russian language and literature, school and University philological education. e-mail: lyuba.gordeeva.85@mail.ru

Place of work: Novokuznetsk Institute (branch) Kemerovo state University, faculty of Philology, Department of Russian language and literature; Novokuznetsk, 34 Radishcheva str., sq. 21, index: 654086, Russia. 